\title{
Nanoscale Clustering of Alcoholic Solutes in Deep Eutectic Solvents Studied by Nuclear Magnetic Resonance and Dynamic Light Scattering
}

DOI:

10.1021/acssuschemeng.9b03771

\section{Document Version}

Accepted author manuscript

Link to publication record in Manchester Research Explorer

Citation for published version (APA):

Häkkinen, R., Alshammari, O., Timmermann, V., D'agostino, C., \& Abbott, A. P. (2019). Nanoscale Clustering of Alcoholic Solutes in Deep Eutectic Solvents Studied by Nuclear Magnetic Resonance and Dynamic Light Scattering. ACS Sustainable Chemistry \& Engineering. https://doi.org/10.1021/acssuschemeng.9b03771

Published in:

ACS Sustainable Chemistry \& Engineering

\section{Citing this paper}

Please note that where the full-text provided on Manchester Research Explorer is the Author Accepted Manuscript or Proof version this may differ from the final Published version. If citing, it is advised that you check and use the publisher's definitive version.

\section{General rights}

Copyright and moral rights for the publications made accessible in the Research Explorer are retained by the authors and/or other copyright owners and it is a condition of accessing publications that users recognise and abide by the legal requirements associated with these rights.

\section{Takedown policy}

If you believe that this document breaches copyright please refer to the University of Manchester's Takedown Procedures [http://man.ac.uk/04Y6Bo] or contact uml.scholarlycommunications@manchester.ac.uk providing relevant details, so we can investigate your claim.

\section{OPEN ACCESS}



Studied by Nuclear Magnetic Resonance and Dynamic Light Scattering

Riina Häkkinen, Odeh Alshammari, Vanessa Timmermann, Carmine D’Agostino, and Andrew P Abbott

ACS Sustainable Chem. Eng., Just Accepted Manuscript • DOI: 10.1021/

acssuschemeng.9b03771 • Publication Date (Web): 06 Aug 2019

Downloaded from pubs.acs.org on August 15, 2019

\section{Just Accepted}

"Just Accepted" manuscripts have been peer-reviewed and accepted for publication. They are posted online prior to technical editing, formatting for publication and author proofing. The American Chemical Society provides "Just Accepted" as a service to the research community to expedite the dissemination of scientific material as soon as possible after acceptance. "Just Accepted" manuscripts appear in full in PDF format accompanied by an HTML abstract. "Just Accepted" manuscripts have been fully peer reviewed, but should not be considered the official version of record. They are citable by the Digital Object Identifier (DOIß). "Just Accepted" is an optional service offered to authors. Therefore, the "Just Accepted" Web site may not include all articles that will be published in the journal. After a manuscript is technically edited and formatted, it will be removed from the "Just Accepted" Web site and published as an ASAP article. Note that technical editing may introduce minor changes to the manuscript text and/or graphics which could affect content, and all legal disclaimers and ethical guidelines that apply to the journal pertain. ACS cannot be held responsible for errors or consequences arising from the use of information contained in these "Just Accepted" manuscripts. 


\title{
Nanoscale Clustering of Alcoholic Solutes in Deep Eutectic Solvents Studied by Nuclear Magnetic Resonance and Dynamic Light Scattering
}

\author{
Riina Häkkinen ${ }^{\dagger}$, Odeh Alshammari ${ }^{\ddagger}, V^{2}$ anessa Timmermann ${ }^{\ddagger}$, Carmine D’Agostino ${ }^{\S}$, Andrew Abbott*‡ \\ †VTT Technical Research Centre of Finland Ltd, Tietotie 4 E, FI-02150 VTT, Finland, riina.hakkinen@vtt.fi, +358 \\ 207225654 \\ ҒChemistry Department, University of Leicester, Leicester, LE1 7RH, UK, apa1@leicester.ac.uk \\ ¿School of Chemical Engineering and Analytical Science, The University of Manchester, The Mill, Sackville Street, \\ Manchester, M13 9PL, UK, carmine.dagostino@manchester.ac.uk
}

\begin{abstract}
It was previously shown that water distributes heterogeneously in deep eutectic solvents (DESs). The aim of this study was to see whether this behavior was common to other hydrogen bonding compounds and determine when a solute formed an emulsion or a homogeneous solution. Pulsed field gradient (PFG) and nuclear Overhauser effect (NOE) NMR, and dynamic light scattering (DLS) are employed to probe the phase behavior of glucose, 1-pentanol and phenol in Ethaline (ethylene glycol: choline chloride, 2:1). By comparing the measured values of self-diffusivities to those calculated assuming Stokesian behavior, it was discovered that glucose forms a homogeneous solution, whereas 1-pentanol forms a heterogeneous mixture. A change in aggregates size of 10 wt\% phenol in Ethaline is observed at $313 \mathrm{~K}$. Above $313 \mathrm{~K}$ aggregation is enhanced and larger aggregates are formed, suggesting a melting of phenol affects the phase behavior. $\left\{{ }^{1} \mathrm{H},{ }^{1} \mathrm{H}\right\}-N O E S Y$ NMR showed that glucose interacts strongly with Ethaline whilst with 1-pentanol and phenol this interaction is weaker. DLS experiments further indicated the heterogeneity and homogeneity. Results suggest that solid solutes that are capable of strong hydrogen bonding are soluble in DESs whereas liquid solutes form heterogeneous nanophases due to the weaker solute - solvent interactions and density difference.
\end{abstract}

\section{Key words}

Aggregation, nanoemulsion, DES, diffusion, solute, nanophase 


\section{Introduction}

Deep eutectic solvents (DESs) are mixtures of a hydrogen bond donor (HBD) and a hydrogen bond acceptor (HBA) mixed together in a suitable ratio. Hydrogen bond formation between the components reduces the melting point of the mixture, and therefore many DESs are liquid at room temperature. The preparation of a DES is simple and atom-efficient, as HBA is just mixed with HBD, and no purification step is needed. By selecting the right combination of a HBD and HBA, the properties of a DES can be easily affected and, hence, tailored for particular applications. Choline chloride $(\mathrm{ChCl})$ is the most commonly used $\mathrm{HBA}$, mainly because it is cheap, non-toxic and biodegradable. ${ }^{1}$ Correspondingly, some of the $\mathrm{ChCl}$-based DESs have proven to be non-toxic and readily biodegradable, i.e. Ethaline (ethylene glycol and $\mathrm{ChCl}, 2: 1$ ), Reline (urea and $\mathrm{ChCl}, 2: 1$ ) and Glyceline (glycerol and $\mathrm{ChCl}, 2: 1) .{ }^{1}$ Furthermore, DESs offer other benefits such as low volatility, low flammability and high thermal stability. ${ }^{2,3}$ These novel solvents have been used as green alternatives for several organic and aqueous solvents on a large scale in different applications..$^{4,5}$

While DESs are connected through strong hydrogen bonding, solutes that can hydrogen bond are expected to have good solubility in DESs. Indeed, DESs are reported to be able to dissolve various solutes including lignocellulosic biomass ${ }^{6}$, pharmaceutical chemicals ${ }^{7}$ and metal oxides ${ }^{4}$. The hydrogen bonding ability of DESs has been utilized especially in extraction, which has recently become a topic of significant interest among researchers. Abbott et al..$^{8}$ emphasized the importance of hydrogen bonding in enabling selective extraction by using a variety of alkanes with different functional groups in six DESs. It was shown that the order for partition coefficient at equilibrium was carboxylic acid > alcohol > ester > ketone, the strongest hydrogen bond donor being the easiest to extract. Wazeer et al. ${ }^{9}$, likewise, used three chloride-based DESs for the separation of benzene from alcohols via liquid-liquid extraction. They discovered that an azeotrope formed between benzene and either methanol or ethanol could be separated if the alcohol content was less than $40 \mathrm{wt} \%$. Above that level, the hydrogen bonds within the DES structure were destroyed. Hammond et al. ${ }^{10}$ also claimed that the critical amount of water in Reline was ca. 42 wt\%. However, all these studies did not quantify the formed aggregate sizes.

The pure DESs are known to form completely homogenous mixtures ${ }^{11}$, whereas aqueous mixtures of DESs undergo microscopic phase separation despite the hydrophilicity of the salt and HBD ${ }^{12}$. D'Agostino et al. ${ }^{12}$ used pulsed field gradient nuclear magnetic resonance (PFG NMR) spectroscopy to probe the phase behavior in Ethaline, Reline and Glyceline with different water contents and revealed that these mixtures form heterogeneous microphases when water content exceeds 2.5 wt\% (1: 1 mole equivalent of water : chloride.). 
Previously, PFG NMR has showed its usefulness in characterizing the mobility of different species, and examining solvent - solvent and solvent - solute interactions in ionic liquids (ILs) and DESs. ${ }^{11-15}$

In this study, PFG NMR, 2D nuclear Overhauser effect spectroscopy (NOESY) NMR and dynamic light scattering (DLS) are used to study the solvent - solute interactions and phase behavior of three alcohols, namely glucose, 1-pentanol and phenol, in Ethaline. Previous studies showed that a low surface tension increased extraction efficiency for thiophene and related compounds. ${ }^{8}$ Therefore, Ethaline, with low surface tension, is a promising solvent for further studies. The solutes were selected based on our previous study on glucose solvation ${ }^{14}$ and partitioning in $\mathrm{DESs}^{8}$. Clustering of solutes to form a microemulsion would negate classical methods of modelling solute solubility.

\section{Experimental section}

Choline chloride (ChCl) ( $\geq 98 \%)$, ethylene glycol (EG) ( $\geq 99 \%)$, glucose ( $\geq 99.5 \%)$, 1-pentanol ( $\geq 99 \%)$ and phenol $(\geq 99 \%)$ were purchased from Sigma Aldrich, and used as received. Ethaline was prepared by mixing ChCl and EG in 1:2 ratio at $333 \mathrm{~K}$ until a homogeneous liquid was formed. The water content of the solutions were measured using volumetric Karl-Fischer titrator with a 'Hydranal ${ }^{\circledR}$ Composite $5^{\prime}$ solution, and found to be $0.57 \pm 0.04$ wt\%.

The viscosity of the mixtures was measured using an Anton Paar Physica MCR 301 cone/plate rheometer with a CP50-2/TG spindle. The instrument was equipped with a temperature control unit, allowing the investigation at different temperatures from $298 \mathrm{~K}$ to $328 \mathrm{~K}$. Four samples per temperature were measured. The viscosity was studied as a function of shear rate from $1 \mathrm{~s}^{-1}$ to $400 \mathrm{~s}^{-1}$. The determined viscosities are an average of the measurements and stabilized viscosity values were recorded. The standard deviation for each viscosity value is presented in ESI.

NMR measurements were performed on a Bruker Avance III HD spectrometer operating at a ${ }^{1} \mathrm{H}$ frequency of 400.13 MHz with a direct-detection (BBO) probe. Equipped with z-Gradient, this probe was capable of producing gradient pulses of up to $50.1 \mathrm{G} / \mathrm{cm} .5 \mathrm{~mm}$ NMR tubes with 7 inch length were used. ${ }^{1} \mathrm{H}$ and $\left\{{ }^{1} \mathrm{H},{ }^{1} \mathrm{H}\right\}-\mathrm{NOESY}$ were recorded at $298 \mathrm{~K}$ and capillary inserts with DMSO- $d_{6}$ used for internal reference. ${ }^{1} \mathrm{H}$ DOSY NMR spectra were measured as bulk liquids from $298 \mathrm{~K}$ up to $328 \mathrm{~K}$ in $5 \mathrm{~K}$ increments. Per temperature controlled measurement the sample was left at set temperature for a minimum of 15 minutes before acquisition to let it reach thermal equilibrium. As the growth of the NOE has a linear dependence on mixing time ${ }^{16}$, and should be adjusted for each solution, 2D NOESY spectra were recorded with mixing times of $100 \mathrm{~ms}, 300 \mathrm{~ms}, 500 \mathrm{~ms}$ and $700 \mathrm{~ms}$ each with gradient pulses applied during the mixing time. PFG NMR was used to acquire ${ }^{1} \mathrm{H}$ DOSY NMR spectra with the 
STE pulse sequences. Maximum values of $4 \mathrm{~ms}$ pulse duration $(\delta)$ and $400 \mathrm{~ms}$ observation $(\Delta)$ were needed to reach the desired diffusion signal attenuation with the gradient $g$ varied in 16 linearly spaced increments. ${ }^{17}$ Regression analysis with the Bruker software TopSpin ${ }^{\circledR} 4.0 .6$ was used to obtain the values of self-diffusion coefficients. The error for self-diffusion coefficients was estimated to be 3-5\%.

The diameters of the solute particles in Ethaline were measured using a Nano-S Zetasizer (Malvern Instruments, UK) at $298 \mathrm{~K}$ and $323 \mathrm{~K}$. The samples were filtered through PTFE membrane syringe filters, with a pore size of $0.45 \mu \mathrm{m}$. Correlograms, cumulants and distribution fits were used to validate the obtained data.

\section{Results and Discussion}

\section{Intermolecular interactions - viscosity}

In general, DESs show higher viscosity than most molecular solvents due to the strong interactions holding the DES components together. Abbott et al. ${ }^{18}$ rationalized the high viscosity of DESs by using the hole theory. According to this theory, the small void size of DESs restricts the movement of species and therefore results in high viscosity. ${ }^{18}$ Figure 1 shows the viscosity of pure Ethaline ${ }^{11}$ and 10 wt\% solutes (glucose, 1-pentanol and phenol) in Ethaline as a function of temperature from 298 to $328 \mathrm{~K}$. The obtained viscosities are in good agreement with previous viscosity studies in DESs. ${ }^{3,12,19}$

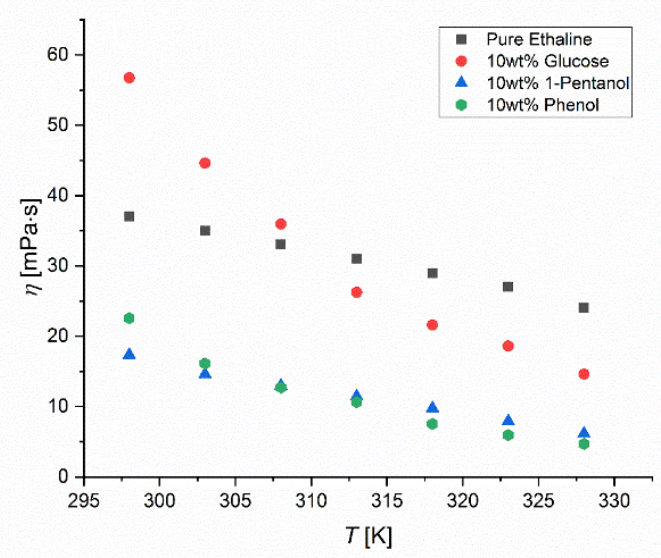

Figure 1. Viscosity of $10 \mathrm{wt} \%$ solutes (glucose, 1-pentanol and phenol) in Ethaline and pure Ethaline ${ }^{11}$ as a function of temperature from 298 to $328 \mathrm{~K}$.

The viscosity of $10 \mathrm{wt} \%$ glucose in Ethaline was higher than in pure Ethaline below $308 \mathrm{~K}$, but lower at higher temperatures. This indicates that glucose can form favorable interactions with Ethaline, but these interactions 
are disturbed at higher temperatures leading to a significant decrease of viscosity. It is commonly known that temperature weakens hydrogen bonding. Therefore, glucose most probably forms hydrogen bonds with Ethaline through its many hydroxyl groups, and these interactions can be significantly affected by temperature. On the other hand, it has been observed that the weakening of hydrogen bonds does not lead to lower viscosity in 1,3dialkylimidazolium-based ILs. ${ }^{20}$ As DESs are formed via hydrogen bonding, it might be that not only the hydrogen bonds of the solute-solvent are affected, but also those of the solute-solute and solvent-solvent. Therefore, it is possible that the hydrogen bonds of the solvent-solvent weaken faster than those of the solute-solute, thus facilitating fluidity. The viscosity of $10 \mathrm{wt} \%$ 1-pentanol and phenol in Ethaline was less than in pure Ethaline and $10 \mathrm{wt} \%$ glucose in Ethaline indicating weaker interactions as these systems have only one hydroxyl group for hydrogen bond formation. In summary, these results on viscosity suggest that glucose forms stronger interactions with Ethaline than 1-pentanol and phenol which suggests a greater degree of structure in the solution.

\section{Diffusion of species in Ethaline}

The addition of a solute (glucose, 1-pentanol and phenol) into Ethaline introduces a second HBD and the relative interactions between the anion/cation and both HBDs will affect the diffusion coefficients of each component. To assess the effect of the solute on mobility and intermolecular interactions between the $\mathrm{Ch}^{+}$cation and EG, the self-diffusivities of four species, namely aliphatic $\mathrm{Ch}^{+}, \mathrm{OH}$ on $\mathrm{Ch}^{+}$, aliphatic $\mathrm{EG}$ and $\mathrm{OH}$ on $\mathrm{EG}$ were examined. The diffusion coefficients measured using the $\mathrm{CH}_{2}$ in $\mathrm{ChCl}$ resonance yield the same value as $\mathrm{CH}_{3}$ in $\mathrm{Ch}^{+}$, as expected, and therefore only that measured using the $\mathrm{CH}_{3}$ moiety is presented in Figure 2. Likewise, $\mathrm{EG} \mathrm{OH}$ and EG $\mathrm{CH}_{2}$ have the same mobility (see ESI, electronic supporting information), meaning that hydroxyl protons remain bound to the rest of the molecule as they diffuse.

Figure 2 shows the self-diffusion coefficients of the $\mathrm{Ch}^{+}$aliphatic protons for $10 \mathrm{wt} \%$ glucose, phenol and 1pentanol as a function of fluidity $\left(\eta^{-1}\right)$ achieved by varying the temperature of the solutions from 298 to $328 \mathrm{~K}$. As for the trend of diffusion coefficients, it can be seen that an increase in fluidity $\left(\eta^{-1}\right)$, the latter being an increasing function of temperature, leads to an increase of diffusion coefficients in all cases, which is expected, and an increase in fluidity means a decrease in liquid viscosity. The strong hydrogen bonding interactions between glucose and Ethaline increase viscosity and slow the mobility of all species being reflected in lower selfdiffusion values than in other solutes in Ethaline and pure Ethaline ${ }^{12}$ (Figure 2). 


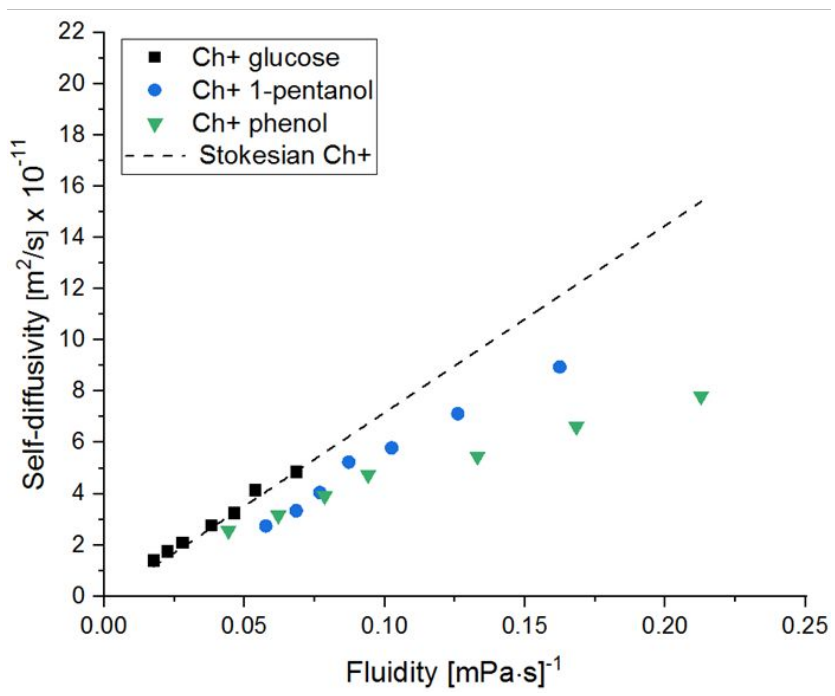

Figure 2. Self-diffusivities of $\mathrm{Ch}^{+}$aliphatic species in $10 \mathrm{wt} \%$ glucose, 1-pentanol and phenol in Ethaline as a function of fluidity achieved by varying the temperature of the solutions from 298 to $328 \mathrm{~K}$. The dashed line shows the Stokesian behavior of $\mathrm{Ch}^{+}$.

The use of the Stokes-Einstein model, eq 1, can help to understand diffusion mechanisms with the mixture. ${ }^{21}$

$$
D=\frac{k T}{6 \pi \eta r}
$$

In eq $1 D$ is diffusivity, $k$ is the Boltzmann constant, $T$ is the temperature, $\eta$ the viscosity, and $r$ is the radius of the diffusing solute molecule.

Comparing the experimentally measured diffusivity of the $\mathrm{Ch}^{+}$aliphatic species (Figure 2) with that expected from Stokes-Einstein calculations, i.e., theoretical line calculated for $\mathrm{Ch}^{+}$using eq 1 and assuming the hard sphere radius of $3.29 \AA$ for $\mathrm{Ch}^{+}$(calculated using a Hartree-Fock model and used previously) ${ }^{12,22}$ it is possible to see a good correlation between the measured and calculated values for $\mathrm{Ch}^{+}$for the $10 \mathrm{wt} \%$ glucose in Ethaline sample. This suggests that aliphatic $\mathrm{Ch}^{+}$diffuses in a Stokesian manner. The validity of the Stokes-Einstein relation in describing the diffusion of $\mathrm{Ch}^{+}$in the glucose-based sample indicates that $\mathrm{Ch}^{+}$species tend to diffuse as isolated species in a continuous medium. This is different to that observed when $10 \mathrm{wt} \%$ water was added to Ethaline when a heterogeneous liquid was formed. ${ }^{12}$

For the two Ethaline samples containing phenol and 1-pentanol, also shown in Figure 2, $\mathrm{Ch}^{+}$diffuses slower than predicted from a Stokesian model. This is similar to that experienced by aliphatic $\mathrm{Ch}^{+}$in Ethaline when water was 
added as a solute as shown in a previous study. ${ }^{12}$ This suggests that the $\mathrm{Ch}^{+}$diffuses in a phase which is more viscous than the bulk viscosity indicating heterogeneities in the mixture, which can be ascribed to the formation of larger, slower diffusing clusters of molecules due to self-aggregation. Previously, the tendency for selfaggregation has been observed also in several ILs. ${ }^{14,23,24}$ Analysis of the diffusion data in Figure 2 for phenol shows that unlike the other two samples, there is a change in the slope for the $\mathrm{Ch}^{+}$cation diffusion trend, which occurs at about $313 \mathrm{~K}$, with the values of self-diffusivity becoming significantly increasingly lower than those calculated using the Stokesian model above this temperature. This suggests that above $313 \mathrm{~K}$ aggregation becomes more significant and aggregates are formed relative to the behavior below $313 \mathrm{~K}$. Such results can be explained by considering solvation effects. Interestingly, the melting point of phenol is $313 \mathrm{~K}$ and the above results could suggest that, below $313 \mathrm{~K}$ phenol is present in solution as a soluble solid, hence there is an effective solvation by $\mathrm{Ch}^{+}$leading to a more homogenous mixture. Above $313 \mathrm{~K}$ the phenol-chloride interactions might be weaker leading to an increase in the phenol-phenol interactions and an increase in aggregation. In simple terms, a weakening of solvent - solute interactions with increasing temperature (i.e., fluidity) favors self-aggregation of the solvent (DES) species, which becomes more significant above the melting point of the phenol solute. This also suggest that above $313 \mathrm{~K}$ the liquid tends to form distinct nanophases, in particular solvent-rich and soluterich phases. The behavior of phenol in Ethaline is opposite to that observed in phenol in water mixtures, which show an upper critical solution temperature at $340 \mathrm{~K}$ and $33.9 \mathrm{wt} \%$ phenol, which is the critical point for the mixture where the two liquids become in one phase and completely miscible. ${ }^{25}$

Comparing the diffusivity of $\mathrm{Ch}^{+} \mathrm{OH}$ and $\mathrm{Ch}^{+}$aliphatic, it can be seen that as fluidity increases the difference between the $\mathrm{Ch}^{+} \mathrm{OH}$ and $\mathrm{Ch}^{+}$aliphatic diffusion coefficients increases (see ESI). This behavior was not seen in pure Ethaline, as the $-\mathrm{OH}$ diffusion of $\mathrm{Ch}^{+}$and $\mathrm{EG}$ remained the same as the aliphatic counterpart ${ }^{12}$ indicating that in pure Ethaline there is no significant proton exchange between $\mathrm{Ch}^{+}$and $\mathrm{EG}$. Interestingly, $\mathrm{Ch}^{+} \mathrm{OH}$ and EG have the same mobility in the glucose solution up to a fluidity of $0.045 \mathrm{mPa} \cdot \mathrm{s}^{-1}$ (Figure 3), meaning that $\mathrm{Ch}^{+} \mathrm{OH}$ is apparently attached to EG below that level. However above that, the mobility of the $\mathrm{Ch}^{+} \mathrm{OH}$ proton increases. This indicates that glucose enhances significantly the proton mobility of the $\mathrm{Ch}^{+} \mathrm{OH}$ proton. This could be due to a Grotthuss mechanism, whereby protons jumps across glucose molecule via hydrogen-bonding facilitating proton mobility. ${ }^{26} \mathrm{~A}$ Grotthuss-like proton hopping has also been observed between the ionic and neutral species in protic and pseudo-protic ILs. ${ }^{27,28}$ These results suggest that glucose is the best facilitator for the exchange between $\mathrm{Ch}^{+} \mathrm{OH}$ and EG, indicating that it tends to homogenize the liquid structuring more than 1-pentanol and phenol. The proton exchange between $\mathrm{Ch}^{+} \mathrm{OH}, \mathrm{EG} \mathrm{OH}$ and water was also seen in high water amounts in aqueous Ethaline mixtures ${ }^{12}$. 
The self-diffusivity data above appear to show that solid solutes capable of hydrogen bonding form homogeneous solutions whereas liquid solutes form more heterogeneous mixtures.

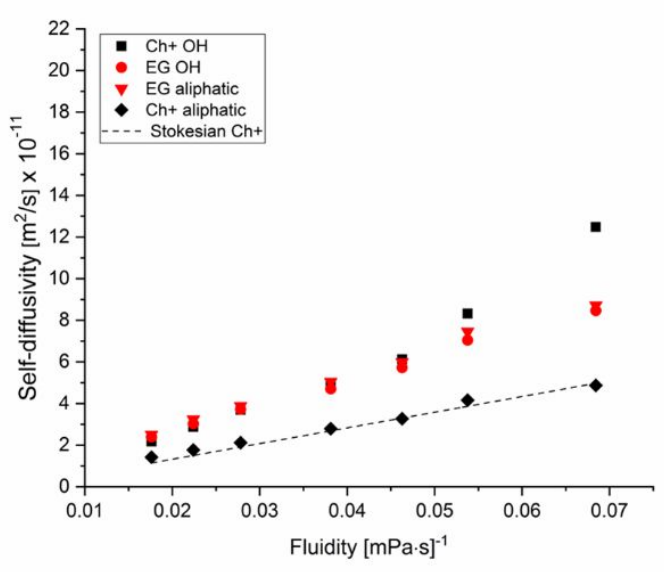

Figure 3. Self-diffusivities of different species in $10 \mathrm{wt} \%$ glucose in Ethaline as a function of fluidity achieved by varying the temperature of the solutions from 298 to $328 \mathrm{~K}$. The dashed line shows the Stokesian behavior of $\mathrm{Ch}^{+}$.

\section{Size distribution -DLS measurements}

DLS was used to investigate the aggregation of solutes in Ethaline with $10 \mathrm{wt} \%$ solute in Ethaline samples at 298 $\mathrm{K}$ and $323 \mathrm{~K}$. The results obtained by PFG NMR measurements suggested that solid solutes form homogeneous solutions whereas liquid solutes cluster to form nanoscale emulsions. DLS will not only confirm this but will provide information about cluster size. Viscosity and refractive index of solutions were measured before the DLS measurements, as these parameters are needed for particle size distribution calculations. The reported size distributions were obtained from the values that gave the best cumulants and distribution fits.

DLS experiments did not show any aggregates for either $10 \mathrm{wt} \%$ glucose in Ethaline at both temperatures and 10wt\% phenol in Ethaline at $298 \mathrm{~K}$ confirming that the solid solutes formed homogeneous solutions. Furthermore, DLS confirmed that aggregates form when $10 \mathrm{wt} \%$ 1-pentanol is dissolved in Ethaline at both temperatures, and a phase difference is observed in $10 \mathrm{wt} \%$ phenol in Ethaline at $323 \mathrm{~K}$ as seen in Figure 4 . It is worth mentioning that PFG NMR is more sensitive to smaller aggregates, whereas DLS to larger. ${ }^{29}$ Therefore, DLS measurement might have reached its limit in the case of phenol at $298 \mathrm{~K}$. In particular, the average aggregate size for $10 \mathrm{wt} \%$ 1-pentanol in Ethaline at both temperatures was $3.2 \pm 1.0 \mathrm{~nm}$, whereas for $10 \mathrm{wt} \%$ phenol at 323 $\mathrm{K} 1.58 \pm 0.5 \mathrm{~nm}$ as seen in Figure 4, which is at lower sensitivity of DLS. The obtained values are significantly 
Figure 4. Size distribution by intensity of (green) $10 \mathrm{wt} \%$ 1-pentanol in Ethaline at $298 \mathrm{~K}$, size $3.20 \pm 1.0 \mathrm{~nm}$, (blue) 10 wt\% 1-pentanol in Ethaline at $323 \mathrm{~K}, 3.24 \pm 1.0 \mathrm{~nm}$, and (red) $10 \mathrm{wt} \%$ phenol in Ethaline at $323 \mathrm{~K}, 1.59$ $\pm 0.5 \mathrm{~nm}$.

An illustrative scheme of the systems is presented in Figure 5. The intermolecular forces between solute and solvent particles must be strong enough to compete with those between solute particles and those between solvent particles in order to be completely soluble and miscible. It is clear that solute - solvent interactions dominate in $10 \mathrm{wt} \%$ glucose in Ethaline as the particles are homogenously distributed to the liquid, and solvated by Ethaline. This is not surprising taking into account that glucose has many hydroxyl groups to form strong hydrogen bonds with Ethaline. In contrast, solute - solute interactions dominate in 10 wt\% 1-pentanol in Ethaline at both temperatures as the particles are heterogeneously distributed to the liquid, and 1-pentanol cannot form as strong interaction with Ethaline as glucose. In $10 \mathrm{wt} \%$ phenol in Ethaline on the other hand, solute - solute, solute - solvent and solvent - solvent interactions are equally represented at $298 \mathrm{~K}$, but at $323 \mathrm{~K}$ greater solute solute interactions and weakened solute - solvent interactions cause larger aggregate formation. 


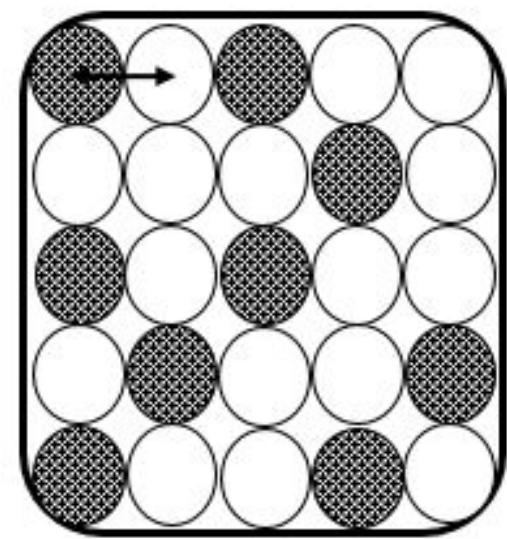

$10 w t \%$ glucose in Ethaline at $298 \mathrm{~K}$ and $323 \mathrm{~K}$

\section{HOMOGENEOUS}

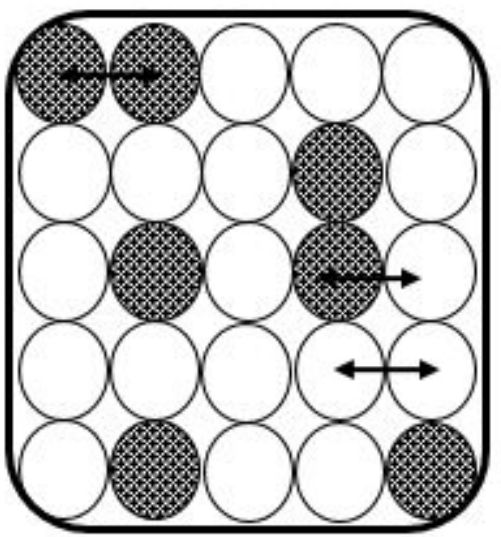

$10 w t \%$ phenol in Ethaline at $298 \mathrm{~K}$

HETEROGENEOUS

Small aggregates

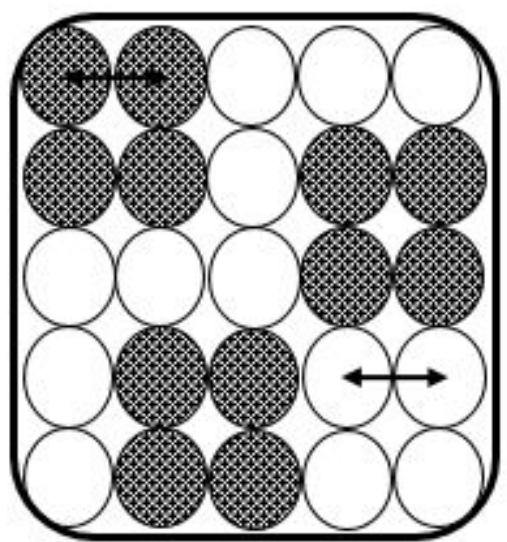

10wt\% 1-pentanol in Ethaline at $298 \mathrm{~K}$ and $323 \mathrm{~K}$

\section{$10 \mathrm{wt} \%$ phenol in Ethaline} at $323 \mathrm{~K}$

\section{HETEROGENEOUS}

Large aggregates

Figure 5. Phase behavior of $10 \mathrm{wt} \%$ glucose, 1-pentanol, and phenol in Ethaline at $298 \mathrm{~K}$ and $323 \mathrm{~K}$.

\section{NOESY -solute-solvent interactions}

$\left\{{ }^{1} \mathrm{H},{ }^{1} \mathrm{H}\right\}$-NOESY NMR spectra were measured of all $10 \mathrm{wt} \%$ solutes in Ethaline and pure Ethaline to investigate the intermolecular behavior and in some extent the phase behavior.

\section{Solute-solvent interactions in pure Ethaline}

In pure Ethaline, cross-peaks showing intramolecular connectivity are observed as expected (Figure 6 b). Furthermore, it is shown that the methylene units of EG are in proximity to the aliphatic protons of $\mathrm{ChCl}$ and both hydroxyl protons show exchange. The individual components, $\mathrm{ChCl}$ and $\mathrm{EG}$, show intramolecular NOE signals. Positive intermolecular NOE signals are also observed between $\mathrm{Ch}^{+} \mathrm{OH}$ and $\mathrm{EG} \mathrm{CH}_{2}$, and EG $\mathrm{OH}$ and $\mathrm{Ch}^{+}$ $\mathrm{C} 1 \mathrm{CH}_{2}$ proving the strong interaction of both components that form the building block of this DES.

Looking at the spectrum obtained for $10 \mathrm{wt} \%$ glucose in Ethaline (Figure $6 \mathrm{~d}$ ), some similarities can be seen. EG and $\mathrm{ChCl}$ show intramolecular and intermolecular connectivity, meaning that the DES structure is not destroyed. In addition, a strong interaction of the glucose protons with both $\mathrm{EG}$ and $\mathrm{ChCl}$ protons is observed and are more 
prominent for the resonances that are further downfield shifted. The hydroxyl protons of glucose show exchange with the other hydroxyl protons in the DES. Even for the aliphatic protons cross-peaks can be seen with the DES hydroxyl protons, caused by the proximity of both molecules. The most evident difference is that the amount of intense positive NOEs, especially intermolecular connectivity between $\mathrm{EG}$ and $\mathrm{ChCl}$, has significantly decreased. This emphasizes the fact that $10 \mathrm{wt} \%$ glucose weakens the interaction between $\mathrm{ChCl}$ and $\mathrm{EG}$, and shows a homogeneous distribution between both components.

10 wt\% 1-pentanol in Ethaline (Figure $6 \mathrm{f}$ ) shows a different behavior. The dominant part of the spectrum shows the inter- and intra-molecular connections between $\mathrm{EG}$ and $\mathrm{ChCl}$ as seen for pure Ethaline. Moreover, positive NOE cross-peaks between $\mathrm{ChCl}$ and EG are observed, indicating that the strong DES-DES interactions are maintained. However, this NOESY spectrum only features further cross-peaks indicating weak interactions of the aliphatic chain of 1-pentanol with the methyl protons of $\mathrm{ChCl}$. Exchange between all hydroxyl protons in the solution can be seen as expected. Altogether this gives rise to the assumption that 1-pentanol is merely sparsely interacting with the DES and shows a more heterogeneous behavior. 
a)

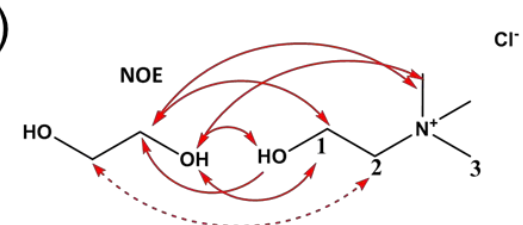

b)

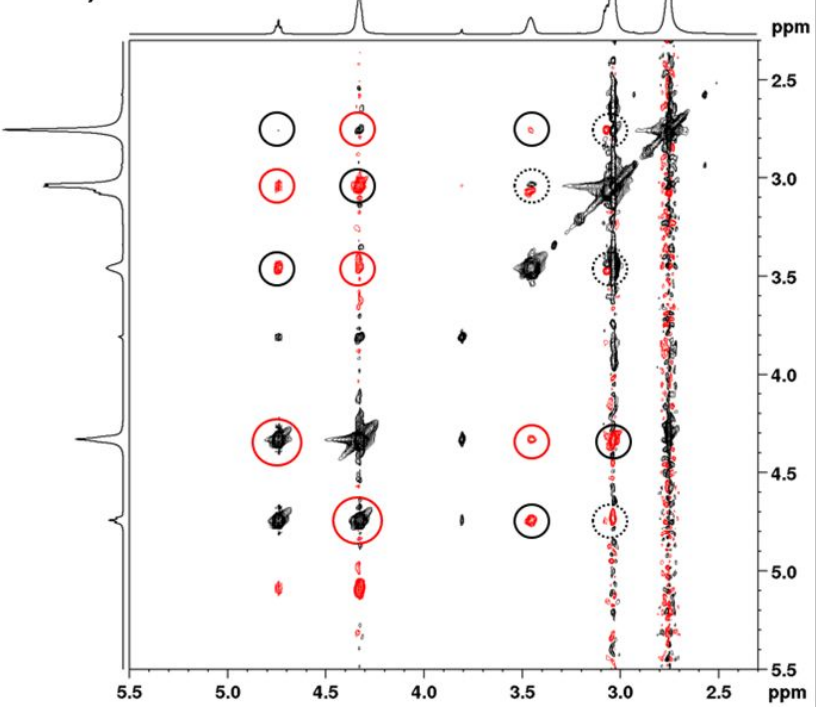

e)

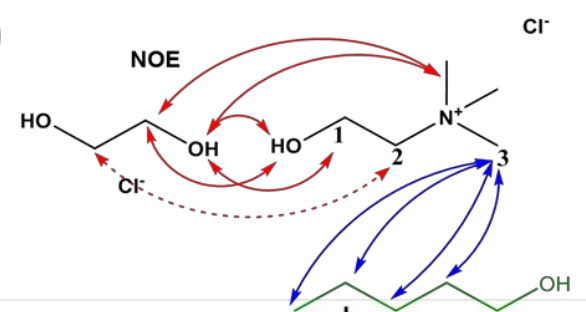

f)

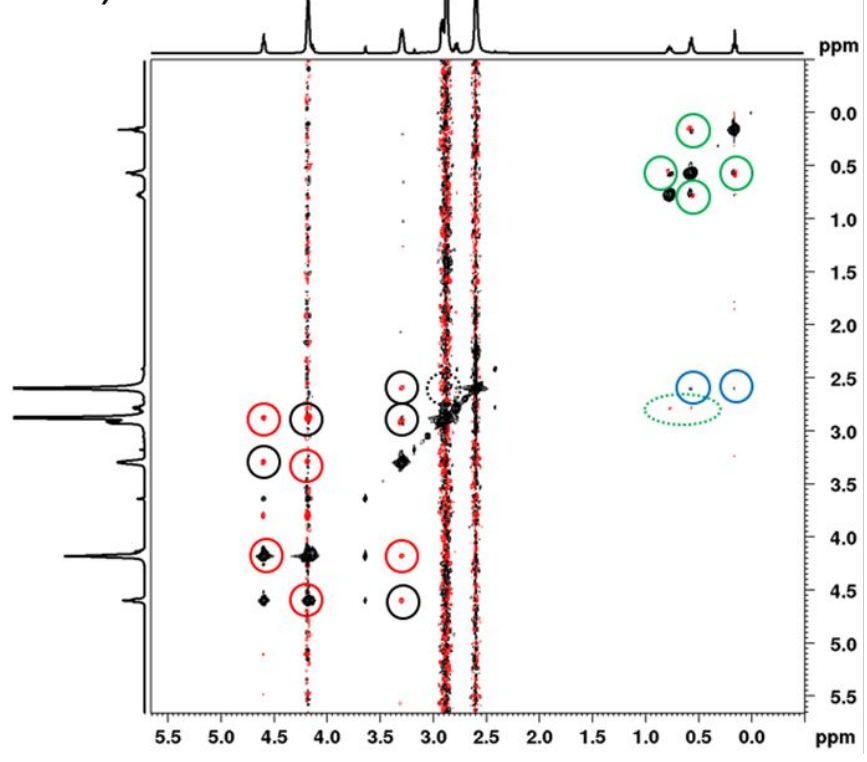

c)

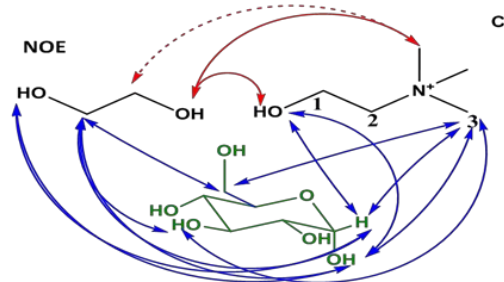

d)

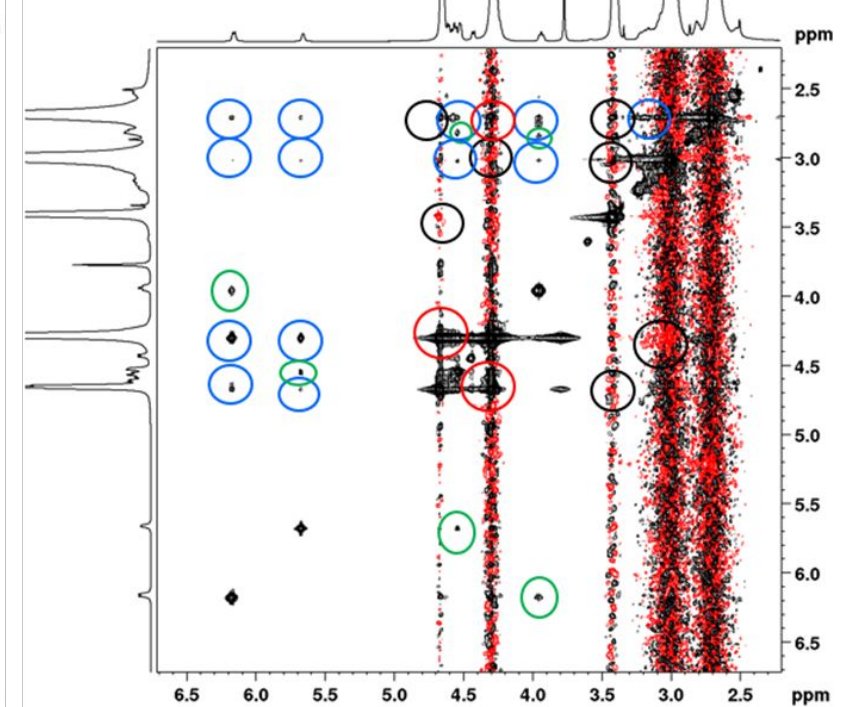

g)

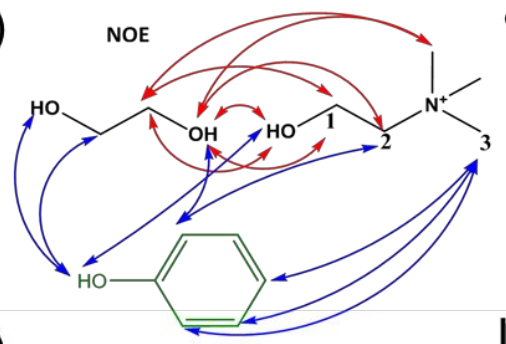

h)

$\mathrm{Cl}^{-}$

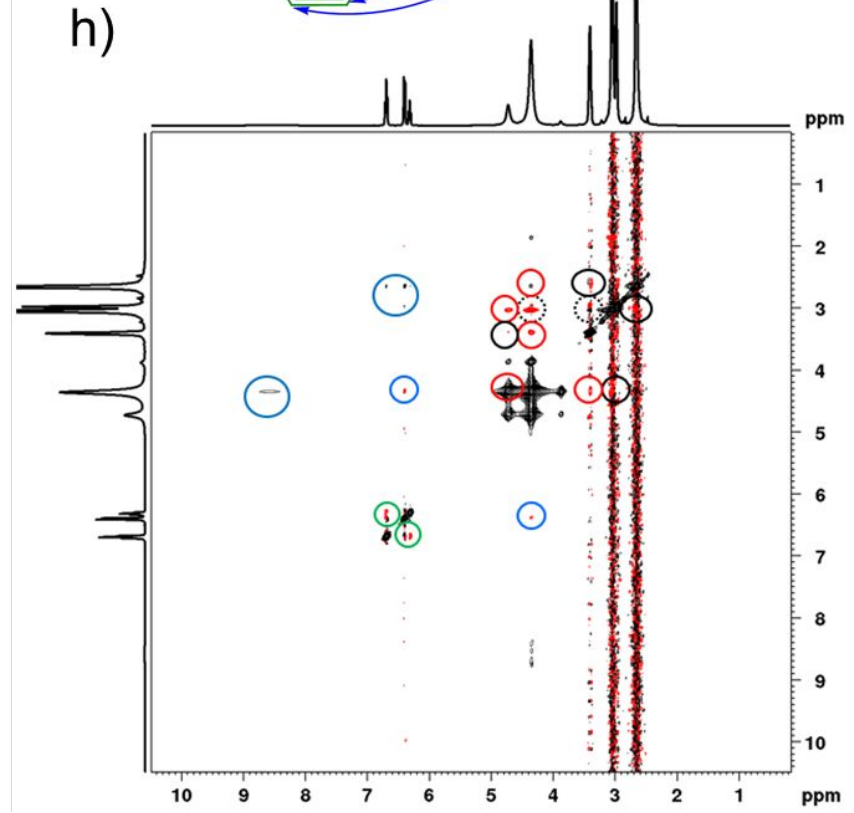




\section{Conclusions}

We demonstrated that three alcoholic solutes (glucose, 1-pentanol and phenol) behave differently in Ethaline. PFG NMR measurements revealed that introduction of solute molecules to Ethaline affects the $-\mathrm{OH}$ proton dissociation in $\mathrm{Ch}^{+}$, which is ascribed to glucose being the best facilitator, suggesting that it tends to homogenize the liquid structuring more than 1-pentanol and phenol. This is further supported by Stokesian behavior of the glucose sample, and with $\left\{{ }^{1} \mathrm{H},{ }^{1} \mathrm{H}\right\}-N O E S Y$ and DLS data. Larger aggregates are formed above $313 \mathrm{~K}$ in $10 \mathrm{wt} \%$ phenol in Ethaline, suggesting a melting of phenol affects the phase behavior. As glucose forms a homogenous mixture, but 1-pentanol heterogeneous phases at nanoscopic level, and phenol larger aggregates above its 
melting point these findings suggest that solid solutes favor to form a homogenous mixture whereas liquid solutes heterogeneous. Most probably, the phase behavior is driven by hydrogen bonding strength between the solute and the solvent (DES), as DESs are hold together by strong hydrogen bonding. This data provides more understanding on these complex systems and aid the development of DESs as greener alternatives for nonaqueous and hazardous media. Furthermore, nanoscale clustering might be useful in designing self-assembly applications.

\section{Supporting information}

Supporting Information is available free of charge on the ACS Publications website at DOI:

Viscosity values, ${ }^{1} \mathrm{H}$ NMR spectra with peak assignments, PFG NMR attenuation plots, self-diffusion values and ratios.

\section{Author information}

\section{Corresponding Author}

*E-mail: apa1@leicester.ac.uk. Phone: +44 1162522087.

\section{ORCID}

Riina Häkkinen: 0000-0002-4652-9730

Carmine D'Agostino: 0000-0003-3391-8320

Andrew Abbott: 0000-0001-9556-8341

\section{Author Contributions}

The manuscript was written through contributions of all authors. All authors have given approval to the final version of the manuscript.

\section{Notes}

The authors declare no competing financial interest. 


\section{Acknowledgement}

Riina Häkkinen received funding from the Academy of Finland [Grant number 288953] and Odeh Alshammari from the Saudi Arabian Cultural Bureau (OAOA). Vladimir Aseyev is acknowledged for his help with DLS.

\section{Abbreviations}

$\mathrm{Ch}^{+}$, choline cation; $\mathrm{ChCl}$, choline chloride; DES, deep eutectic solvent; DLS, dynamic light scattering; EG, ethylene glycol; IL, ionic liquid; PFG NMR, pulsed field gradient nuclear magnetic resonance

\section{References}

(1) Juneidi, I.; Hayyan, M.; Hashim, M. A. Evaluation of Toxicity and Biodegradability for Cholinium-Based Deep Eutectic Solvents. RSC Adv. 2015, 5 (102), 83636-83647.

(2) García, G.; Aparicio, S.; Ullah, R.; Atilhan, M. Deep Eutectic Solvents: Physicochemical Properties and Gas Separation Applications. Energy \& Fuels 2015, 29 (4), 2616-2644.

(3) Häkkinen, R.; Willberg-Keyriläinen, P.; Ropponen, J.; Virtanen, T. Effect of Composition and Water Content on Physicochemical Properties of Choline Chloride-Boric Acid Low-Melting Mixtures. J. Mol. Liq. 2019, 280, 104-110.

(4) Abbott, A. P.; Capper, G.; Davies, D. L.; McKenzie, K. J.; Obi, S. U. Solubility of Metal Oxides in Deep Eutectic Solvents Based on Choline Chloride. J. Chem. Eng. Data 2006, 51 (4), 1280-1282.

(5) Zhang, C.-W.; Xia, S.-Q.; Ma, P.-S. Facile Pretreatment of Lignocellulosic Biomass Using Deep Eutectic Solvents. Bioresour. Technol. 2016, 219, 1-5.

(6) Lynam, J. G.; Kumar, N.; Wong, M. J. Deep Eutectic Solvents' Ability to Solubilize Lignin, Cellulose, and Hemicellulose; Thermal Stability; and Density. Bioresour. Technol. 2017, 238, 684-689.

(7) Morrison, H. G.; Sun, C. C.; Neervannan, S. Characterization of Thermal Behavior of Deep Eutectic Solvents and Their Potential as Drug Solubilization Vehicles. 2009, 378, 136-139.

(8) Abbott, A. P.; Al-Murshedi, A. Y. M.; Alshammari, O. A. O.; Harris, R. C.; Kareem, J. H.; Qader, I. B.; Ryder, K. Thermodynamics of Phase Transfer for Polar Molecules from Alkanes to Deep Eutectic Solvents. Fluid Phase Equilib. 2017, 448, 99-104. 
(9) Wazeer, I.; Hizaddin, H. F.; El Blidi, L.; Ali, E.; Hashim, M. A.; Hadj-Kali, M. K. Liquid-Liquid Equilibria for Binary Azeotrope Mixtures of Benzene and Alcohols Using Choline Chloride-Based Deep Eutectic Solvents. J. Chem. Eng. Data 2018, 63 (3), 613-624.

(10) Hammond, O. S.; Bowron, D. T.; Edler, K. J. The Effect of Water upon Deep Eutectic Solvent Nanostructure: An Unusual Transition from Ionic Mixture to Aqueous Solution. Angew. Chemie Int. Ed. 2017, 56 (33), 9782-9785.

(11) D’Agostino, C.; Harris, R. C.; Abbott, A. P.; Gladden, L. F.; Mantle, M. D. Molecular Motion and lon Diffusion in Choline Chloride Based Deep Eutectic Solvents Studied by 1H Pulsed Field Gradient NMR Spectroscopy. Phys. Chem. Chem. Phys. 2011, 13 (48), 21383.

(12) D’Agostino, C.; Gladden, L. F.; Mantle, M. D.; Abbott, A. P.; Ahmed, Essa, I.; Al-Murshedi, A. Y. M.; Harris, R. C. Molecular and Ionic Diffusion in Aqueous - Deep Eutectic Solvent Mixtures: Probing InterMolecular Interactions Using PFG NMR. Phys. Chem. Chem. Phys. 2015, 17 (23), 15297-15304.

(13) Keaveney, S. T.; Schaffarczyk McHale, K. S.; Stranger, J. W.; Ganbold, B.; Price, W. S.; Harper, J. B. NMR Diffusion Measurements as a Simple Method to Examine Solvent-Solvent and Solvent-Solute Interactions in Mixtures of the Ionic Liquid [Bmim][N(SO 2 CF 3 ) 2 ] and Acetonitrile. ChemPhysChem 2016, 17 (23), 3853-3862.

(14) D’Agostino, C.; Mantle, M. D.; Mullan, C. L.; Hardacre, C.; Gladden, L. F. Diffusion, Ion Pairing and Aggregation in 1-Ethyl-3-Methylimidazolium-Based lonic Liquids Studied by $1 \mathrm{H}$ and 19 F PFG NMR: Effect of Temperature, Anion and Glucose Dissolution. ChemPhysChem 2018, 19 (9), 1081-1088.

(15) Youngs, T. G. A.; Holbrey, J. D.; Mullan, C. L.; Norman, S. E.; Lagunas, M. C.; D’Agostino, C.; Mantle, M. D.; Gladden, L. F.; Bowron, D. T.; Hardacre, C. Neutron Diffraction, NMR and Molecular Dynamics Study of Glucose Dissolved in the Ionic Liquid 1-Ethyl-3-Methylimidazolium Acetate. Chem. Sci. 2011, 2 (8), 1594.

(16) Claridge, T. D. W. Correlations Through Space: The Nuclear Overhauser Effect. In High-Resolution NMR Techniques in Organic Chemistry; Claridge, T. D. W., Ed.; Elsevier: Boston, 2016; pp 315-380.

(17) Tanner, J. E. Use of the Stimulated Echo in NMR Diffusion Studies. J. Chem. Phys. 1970, 52 (5), 25232526.

(18) Abbott, A. P.; Boothby, D.; Capper, G.; Davies, D. L.; Rasheed, R. K. Deep Eutectic Solvents Formed 
between Choline Chloride and Carboxylic Acids: Versatile Alternatives to Ionic Liquids. J. Am. Chem. Soc. 2004, 126 (29), 9142-9147.

(19) Dietz, C. H. J. T.; Kroon, M. C.; van Sint Annaland, M.; Gallucci, F. Thermophysical Properties and Solubility of Different Sugar-Derived Molecules in Deep Eutectic Solvents. J. Chem. Eng. Data 2017, 62 (11), 3633-3641.

(20) Zahn, S.; Bruns, G.; Thar, J.; Kirchner, B. What Keeps Ionic Liquids in Flow? Phys. Chem. Chem. Phys. 2008, $10(46), 6921$.

(21) Köddermann, T.; Ludwig, R.; Paschek, D. On the Validity of Stokes-Einstein and Stokes-Einstein-Debye Relations in Ionic Liquids and Ionic-Liquid Mixtures. ChemPhysChem 2008, 9 (13), 1851-1858.

(22) D’Agostino, C.; Harris, R. C.; Abbott, A. P.; Gladden, L. F.; Mantle, M. D. Molecular Motion and Ion Diffusion in Choline Chloride Based Deep Eutectic Solvents Studied By1H Pulsed Field Gradient NMR Spectroscopy. Phys. Chem. Chem. Phys. 2011, 13 (48), 21383-21391.

(23) Burrell, G. L.; Burgar, I. M.; Gong, Q.; Dunlop, N. F.; Separovic, F. NMR Relaxation and Self-Diffusion Study at High and Low Magnetic Fields of Ionic Association in Protic Ionic Liquids. J. Phys. Chem. B 2010, 114 (35), 11436-11443.

Scharf, N. T.; Stark, A.; Hoffmann, M. M. Ion Pairing and Dynamics of the Ionic Liquid 1-Hexyl-3Methylimidazolium Bis(Irifluoromethylsulfonyl)Amide ([C 6 Mim][NTf 2 ]) in the Low Dielectric Solvent Chloroform. J. Phys. Chem. B 2012, 116 (37), 11488-11497.

(25) HK, Z.; IR, A. Critical Behavior of the Electrical Conductivity for the Binary Mixture of Water and Phenol. J. Mater. Sci. Eng. 2016, 05 (02), 2-5.

(26) Cukierman, S. Et Tu, Grotthuss! And Other Unfinished Stories. Biochim. Biophys. Acta - Bioenerg. 2006, $1757(8), 876-885$.

(27) Ingenmey, J.; Gehrke, S.; Kirchner, B. How to Harvest Grotthuss Diffusion in Protic Ionic Liquid Electrolyte Systems. ChemSusChem 2018, 11 (12), 1900-1910.

(28) Doi, H.; Song, X.; Minofar, B.; Kanzaki, R.; Takamuku, T.; Umebayashi, Y. A New Proton Conductive Liquid with No lons: Pseudo-Protic lonic Liquids. Chem. - A Eur. J. 2013, 19 (35), 11522-11526. 
Diffusion Coefficients of Formulated Insulin: Implications for Particle Size Distribution Measurements in Drug Products. AAPS J. 2017, 19 (6), 1760-1766.

(30) Komal; Singh, G.; Singh, G.; Kang, T. S. Aggregation Behavior of Sodium Dioctyl Sulfosuccinate in Deep Eutectic Solvents and Their Mixtures with Water: An Account of Solvent's Polarity, Cohesiveness, and Solvent Structure. ACS Omega 2018, 3 (10), 13387-13398.

(31) Kang, T. S.; Ishiba, K.; Morikawa, M.; Kimizuka, N. Self-Assembly of Azobenzene Bilayer Membranes in Binary lonic Liquid-Water Nanostructured Media. Langmuir 2014, 30 (9), 2376-2384.

(32) Sanchez-Fernandez, A.; Moody, G. L.; Murfin, L. C.; Arnold, T.; Jackson, A. J.; King, S. M.; Lewis, S. E.; Edler, K. J. Self-Assembly and Surface Behaviour of Pure and Mixed Zwitterionic Amphiphiles in a Deep Eutectic Solvent. Soft Matter 2018, 14 (26), 5525-5536.

(33) Banjare, M. K.; Behera, K.; Satnami, M. L.; Pandey, S.; Ghosh, K. K. Self-Assembly of a Short-Chain Ionic Liquid within Deep Eutectic Solvents. RSC Adv. 2018, 8 (15), 7969-7979.

\section{Synopsis}

Liquid solutes cluster in deep eutectic solvents, which are considered as green alternatives for petrol-based solvents, whereas solid solutes form homogeneous solutions.
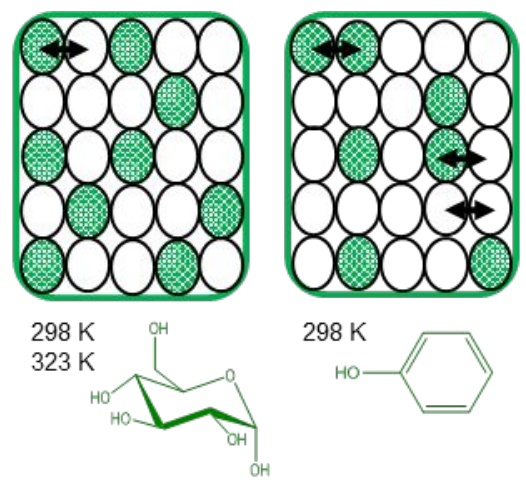

$298 \mathrm{~K}$

$323 \mathrm{~K}$

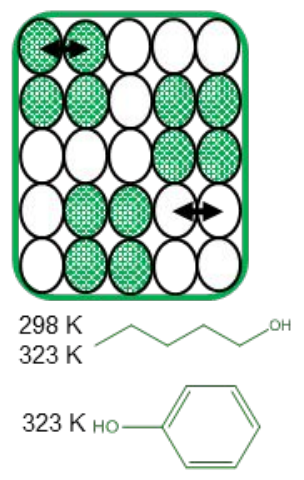

For Table of Contents Use Only 